\title{
Comentarios sobre liderazgo respecto al editorial de la Revista Argentina de Radiología 2018; 82-153: "La necesidad de formar un equipo de trabajo"
}

\section{Comments on leadership regarding the editorial "La necesidad de formar un equipo de trabajo" in Revista Argentina de Radiología 2018; 82-153}

\author{
Juan Cristóbal Valenzuela Claros ${ }^{1}$ \\ ${ }^{1}$ Especialista en Radiodiagnóstico en el Complejo Hospitalario de Jaén \\ y Oncología Médica, España
}

Rev Argent Radiol 2022;85(Suppl S1):S11-S12.

Estimados editores,

En relación al editorial "La necesidad de formar un equipo de trabajo" de Fajre $\mathrm{L}^{1}$ en la Revista Argentina de Radiología, y expresando nuestro total acuerdo con el contenido de su texto, querríamos abundar sobre la importancia de un liderazgo moderno a la hora de conseguir conformar un equipo de trabajo eficiente, sin dejar de lado la inequívoca y necesaria implicación de todos los miembros del grupo de trabajo y sus mecanismos de soporte ya comentados en el texto aludido. Históricamente, ha habido varios análisis y modelos sobre la figura del líder en un equipo de trabajo, sus funciones y las posibilidades que aportarían cada uno de ellos.

En nuestro enfoque cotidiano de la labor en equipo, consideramos dos variables como manifestaciones de liderazgo:

Orientación a la tarea: Es una dimensión de estructura. Identifica el grado en que el líder define la tarea, la estructura, las interacciones en el grupo y asignar roles. Un individuo con alta orientación de ese tipo espera que se mantengan altos niveles de desempeño y enfatiza el cumplimiento de plazos entre otras metas concretas.

Orientación a la relación: Es una dimensión de consideración. El líder muestra interés por sus colaboradores,

received December 18, 2019

accepted

April 15, 2020

published online

August 27, 2020
Address for correspondence Juan Cristóbal Valenzuela Claros, PhD, Av. Ejército Español 10, Jaén, España (e-mail: juancristobalpozi@hotmail.es).

tiene en cuenta sus sentimientos y sensaciones y busca el bienestar del grupo. Individuos con alta puntuación en ese elemento son aquellos que se caracterizan por establecer relaciones personales cordiales, son accesibles, flexibles y tratan a todos por igual.

Una puntuación alta en la dimensión de consideración genera una satisfacción positiva entre los miembros del grupo y una alta puntuación en la dimensión de estructura o tarea genera una alta efectividad.

Cuando hablamos de liderazgo, hablamos de las dinámicas $\mathrm{y}$ los flujos de influencia que se producen dentro de un grupo y que lo orientan hacia el logro. Ese flujo, que normalmente surge a partir de un individuo, el líder, debe impregnar la organización de forma que se cree una cultura de liderazgo compartido, elemento clave para conseguir el compromiso de todos los colaboradores con el resultado final. El ideal sería el líder que generara alta puntuación en ambas dimensiones. Debería profundizarse en métodos objetivos de puntuación de ellas, algunos ya existentes, e intentar implementarlos.

Como recogen Villarreal y col. ${ }^{2}$ en su estudio de gestión de las organizaciones y administración estratégica, esos aspectos del liderazgo y otros han sido analizados en diferentes épocas

(C) 2020. Asociación Civil Sociedad Argentina de Radiología and Federacion Argentina de Asociaciones de Radiología, Diagnóstico por Imágenes y Terapia Radiante. All rights reserved.

This is an open access article published by Thieme under the terms of the Creative Commons Attribution-NonDerivative-NonCommercial-License, permitting copying and reproduction so long as the original work is given appropriate credit. Contents may not be used for commercial purposes, or adapted, remixed, transformed or built upon. (https://creativecommons.org/ licenses/by-nc-nd/4.0/)

Thieme Revinter Publicações Ltda., Rua do Matoso 170, Rio de Janeiro, RJ, CEP 20270-135, Brazil 
por el grupo de Ohio, el de Blake (o Grid gerencial), el situacional, el transaccional-transformacional y otros.

En la actualidad, la tendencia es abandonar cada vez más modelos arcaicos muy jerarquizados y/o verticales. ${ }^{3}$ Kotter $^{4}$ ha definido ocho pasos para transformar una organización y alcanzar el mayor éxito multidimensional posible en sus funciones:

1. Establecer un sentido de urgencia.

2. Formar una coalición de guía poderosa.

3. Crear una visión, una estrategia, una cultura de seguimiento y dar ejemplo.

4. Comunicar adecuadamente dicha visión.

5. Facultar a los demás.

6. Planificar para crear ganancias a corto plazo.

7. Consolidar las mejoras y producir cambios progresivos.

8. Institucionalizar nuevos métodos.

En resumen, el directivo que practique el liderazgo tiene que imponerse asimismo la congruencia entre hechos y palabras y entre conducta, creencias y valores expresados. Debe, asimismo, determinar lo que se pretende lograr de sus colaboradores y del grupo en cuanto a metas y objetivos, sin por ello dejar de adecuar las aspiraciones colectivas a las características de cada uno de los miembros del trabajo de equipo para, sí, crear lo que éste debe ser en realidad, un equipo de trabajo.

\section{Conflicto de Intereses}

El autor declara no tener ningún conflicto de intereses.

\section{Bibliografía}

1 Fajre L. La necesidad de conformar un "equipo de trabajo". Rev Argent Radiol. 2018;82(04):153

2 Villarreal MA, Hernández F, Zamudio C. La Administración Estratégica. Nuevas formas de liderazgo en la empresa. XIX Congreso Internacional de Investigación en Ciencias Administrativas: Gestión de las organizaciones rumbo al 3er milenio, de la regionalización a la globalización. 2014. Universidad Autónoma de Tamaulipas Durango, México

3 Braun S, Peus C, Weisweller S, Frey D. Transformational leadership, job satisfaction, and team performance: A multilevel mediation model of trust. Leadersh Q. 2012;24(01):270-283

4 Kotter JP. Leading Change. Boston, MA: Harvard business review press; 2012 